\title{
Systemic Colonization and Expression of Disease Symptoms on Bittersweet Nightshade (Solanum dulcamara) Infected with a GFP-Tagged Dickeya solani IP02222 (IPO2254)
}

\author{
Jakub Fikowicz-Krosko and Robert Czajkowski, ${ }^{\dagger}$ University of Gdansk, Intercollegiate Faculty of Biotechnology of University of Gdansk
} and Medical University of Gdansk, Department of Biotechnology, Antoniego Abrahama 58, 80-307, Gdansk, Poland

\begin{abstract}
Colonization of Solanum dulcamara (bittersweet nightshade) plants by a GFP-tagged Dickeya solani type strain IPO2222 (IPO2254) was investigated by selective plating and epifluorescence stereomicroscopy (ESM), using in vitro plants and plants grown in compost soil. Replicated experiments were carried out in a growth chamber and the progress of infection and disease symptoms on tissue of the cultured plants, following leaf- and stem-base inoculations with bacteria, was evaluated. Microscopy observations were confirmed by spread-plating dilutions of plant extracts onto agar medium directly after the harvest. In experiments where the stem base of in vitro plants inoculated with a range of inocula of $D$. solani $\left(10^{4}\right.$ to $10^{8}$ colony forming units $[\mathrm{cfu}] \mathrm{ml}^{-1}$ ) was examined at 14 days post infection (dpi),

blackleg-like symptoms developed in more than $80 \%$ plants together with a reduction of the plant fitness (disease symptoms, weight, height, and appearance). In leaf-inoculated plants at $14 \mathrm{dpi}, 15 \%$ of the plants exhibited severe blackleg-like symptoms. In detached $S$. dulcamara leaf assays, IPO2254 survived on the adaxial surface for 14 days at populations of $10^{6} \mathrm{cfu}$ per leaf. Thirty days after stem inoculation of plants grown in compost soil in pots, up to $10^{4} \mathrm{cfu} \mathrm{g}^{-1}$ of GFP-tagged $D$. solani were found inside the stems. D. solani were detected inside the vascular tissue (xylem vessels) of stems, in the pith tissue in roots, and on the internal surface of the stem hollow. The implications of $S$. dulcamara infection by $D$. solani for the long-distance dispersal of the bacterial inoculum are discussed.
\end{abstract}

Solanum dulcamara L. (bittersweet nightshade) is a perennial herbaceous weed, which in the last couple of centuries has been naturalized in many parts of the world. It is one of the 1,500 to 2,000 native Solanum species occurring in Europe and Asia (Weese and Bohs 2007). S. dulcamara has been introduced to North and South America, New Zealand, and Australia, and is now considered as an invasive weed (Forcella and Stephen 1988; Golas et al. 2010a). Bittersweet nightshade may grow in contrasting natural habitats from woodlands and scrublands to hedges and marshes and therefore it is now considered to have a worldwide distribution (Pegtel 1985). Moreover, $S$. dulcamara is often found in direct proximity to potato fields (Toth et al. 2011).

Together with other Solanum species present in Europe, e.g., S. nigrum L. (Flier et al. 2003), bittersweet nightshade is considered a weed of arable fields and an alternative (secondary) host for pathogens affecting potato ( $S$. tuberosum L.) cultivations (Shah et al. 2010). For example, it is well established that $S$. dulcamara is a host for the quarantine pathogen Ralstonia solanacearum, the causal agent of bacterial wilt or brown rot of potato (Álvarez et al. 2010). It has been shown that $S$. dulcamara growing in ditches and near natural water sources used for irrigation of adjacent potato fields harbors relatively large $R$. solanacearum population and allows survival of the pathogen between cropping seasons while the primary host (potato) is absent (Elphinstone et al. 1998). Therefore, in several countries in Europe, S. dulcamara is a subject to extensive eradication programs from its natural habitats, aimed at preventing the spread of $R$. solanacearum. S. dulcamara is also a recognized alternative (secondary) host for Phytophthora infestans, an oomycete pathogen causing potato late blight, one of the most important nonbacterial potato pathogens worldwide (Golas et al. 2010b; van West and Vleeshouwers 2004).

Only limited data are available on the survival of soft rot Enterobacteriaceae: pectinolytic Pectobacterium spp. and Dickeya spp.

${ }^{\dagger}$ Corresponding author: Robert Czajkowski;

E-mail: robert.czajkowski@biotech.ug.edu.pl

Accepted for publication 20 October 2017.

(c) 2018 The American Phytopathological Society
(Pérombelon 2002) on S. dulcamara and no extensive studies have been done so far to address the role of bittersweet nightshade in the spread and the survival of these pathogens in the environment. Olsson (1985) reported the isolation of Dickeya spp. from S. dulcamara growing in watercourses used for irrigation in Sweden (Olsson 1985). We have recently isolated Pectobacterium carotovorum subsp. carotovorum from bittersweet nightshade plants grown in a riparian environment in northern Poland. These isolates were virulent to potato tubers causing typical soft rot symptoms (Fikowicz-Krosko et al. 2017).

Soft rot Enterobacteriaceae (SRE), Pectobacterium spp. and Dickeya spp., are causal agents of blackleg, aerial stem rot, wet rot, and tuber soft rot of potato (S. tuberosum). Both genera are among the top 10 most important bacterial pathogens in agriculture (Mansfield et al. 2012). In Europe, Dickeya spp. cause vast economic losses in (seed) potato production, mainly due to the rejection and reclassification of seed lots. Since 2000, a new species, Dickeya solani (van der Wolf et al. 2014) has been found regularly in association with potato in many European countries, and also isolated from potato grown in Israel and Georgia. Therefore, the increasing losses in seed potato production attributed to Dickeya spp. infection might be related to the spread of D. solani (Toth et al. 2011; van der Wolf et al. 2014).

D. solani is mainly a seedborne pathogen (Czajkowski et al. 2009; Pérombelon, 2000); it is, however, well established that the infection of grown potato plants with pectinolytic bacteria may originate from other sources, e.g., contaminated equipment used for crop spraying, insects feeding on symptomatic plants, contaminated irrigation water, and/or aerosols (Elphinstone and Pérombelon 1986; Toth et al. 2011). Only limited data are available on the survival of pectinolytic bacteria on alternative (secondary) hosts including weeds (Toth et al. 2011; Tsror et al. 2010), and even less is known regarding D. solani. It is, however, very likely that Dickeya spp., as broad host pathogens, can survive on different plant species as it happens in the case of $P$. carotovorum subsp. carotovorum (Ma et al. 2007; Pérombelon and Hyman 1989).

This study aimed to investigate the ability of a type strain GFPtagged D. solani IPO2222 (IPO2254) to infect $S$. dulcamara plants grown in culture tubes or in pots with compost soil in a growth chamber to better understand the impact of $D$. solani and $S$. dulcamara interaction on the epidemiology of soft rot and blackleg of potato. The progression of infection and systemic colonization of plants were studied using a GFP-tagged $D$. solani strain and different inoculation points, i.e., roots and leaves, to evaluate the routes of systemic 
bacterial spread in growing plants. Epifluorescence stereomicroscopy (ESM) was used to localize and visualize the bacteria inside plant tissues in situ, and dilution-plating techniques were used to estimate the bacterial populations and assess D. solani population dynamics inside plants.

\section{Materials and Methods}

Bacterial strains, plants, and growth media. GFP-tagged type strain D. solani IPO2222 (IPO2254) (Czajkowski et al. 2010b; van der Wolf et al. 2014) was grown at $28^{\circ} \mathrm{C}$ for 24 to $48 \mathrm{~h}$ on tryptone soya agar (TSA) (Oxoid) supplemented with $100 \mu \mathrm{g} \mathrm{ml}^{-1}$ ampicillin (Sigma). Liquid bacterial cultures were prepared in tryptone soya broth (TSB) (Oxoid) also supplemented with $100 \mu \mathrm{g} \mathrm{ml}^{-1}$ ampicillin and grown at $28^{\circ} \mathrm{C}$ for $24 \mathrm{~h}$ with agitation (150 to $\left.200 \mathrm{rpm}\right)$.

S. dulcamara in vitro plantlets (accession A54750008, The Experimental Garden and Genebank, Radboud University Nijmegen, the Netherlands) were obtained from Prof. Titti Mariani from Department of Molecular Plant Physiology, Radboud University, Nijmegen, the Netherlands. They were maintained on Murashige and Skoog (MS) medium (Murashige and Skoog 1962) supplemented with Gamborg's vitamin mixture (Duchefa) (MS+G vit.), $30 \mathrm{~g} \mathrm{liter}^{-1}$ sucrose (Chempur), $\mathrm{pH} 5.8$, and solidified with $7 \mathrm{~g} \mathrm{liter}^{-1}$ plant agar (Duchefa) at $22^{\circ} \mathrm{C}$ under $16 / 8 \mathrm{~h}$ photoperiod.

Growth and propagation of $S$. dulcamara in vitro plants. Forty milliliters of autoclaved MS+G vit. medium was poured into $77 \times$ $77 \times 97 \mathrm{~mm}$ Magenta culture vessels (Sigma) and closed with polypropylene Magenta caps (Sigma). Five nodal S. dulcamara explants per vessel were cultured 1 month prior use. All plant cultures were incubated under growth chamber conditions in an Innova 42R phytochamber (Eppendorf) equipped with a photosynthetic light bank (SYLVANIA, GRO-LUX, T8 15W, 8500K), in 16/8 h light/dark regime and temperature of $22 \pm 0.5^{\circ} \mathrm{C}$. Apical nodes of $S$. dulcamara plants with at least two pairs of leaves were harvested from 1-monthold stock cultures and placed individually on $10 \mathrm{ml}$ of $\mathrm{MS}+\mathrm{G}$ vit. medium, in De Wit culture tubes (Duchefa Biochemie bv.). Before inoculation with bacteria, plants were grown for an additional 2 weeks under similar conditions to allow growth of at least 1-cm-long roots and for the stem base cut wound to heal.

Inoculation of in vitro-grown $S$. dulcamara plants with $D$. solani IPO2254 to study systemic colonization initiated from stem base and roots. Inoculation of $\mathrm{S}$. dulcamara plants with $\mathrm{D}$. solani IPO2254. For inoculation of $S$. dulcamara plants, $10 \mu l$ of bacterial suspensions in 1/4 Ringer's buffer (Merck) containing $10^{4}, 10^{6}$, or $10^{8} \mathrm{cfu} \mathrm{ml}^{-1}$ of IPO2254 were pipetted into the interspace between the stem base and the MS medium of each individual plant. For negative control, instead of bacterial suspension, $10 \mu \mathrm{l}$ of sterile 1/4 Ringer's buffer (Merck) was used. Four treatments were applied. Treatment A: plants inoculated with Ringer's buffer (control), Treatment B: plants inoculated with $10^{4} \mathrm{cfu} \mathrm{m}^{-1}$ of IPO2254, Treatment C: plants inoculated with $10^{6} \mathrm{cfu} \mathrm{m}^{-1}$ of IPO2254, and Treatment D: plants inoculated with $10^{8} \mathrm{cfu} \mathrm{ml}^{-1}$ of IPO2254. Each treatment consisted of 20 plants grown in individual culture tubes (Culture Tubes "De Wit", Duchefa Biochemie bv.) and the experiment was repeated independently one time with the same setup.

Symptom development in vitro-grown plants after stem base and root inoculation. Plants were visually inspected 3, 7, 10, and 14 days post inoculation (dpi) for symptom development and were assessed for wilting, blackleg-like symptoms, stem desiccation, and plant death. The height of plants, from the surface of the agar medium to the plant's top, was assessed for each plant at each time point.

Sampling of S. dulcamara plants. Plants were sampled 3, 7, 10, and 14 dpi. At each time point, five plants per treatment were sampled. The plants were aseptically removed from the culture tubes and each (stem and leaves but no roots) was collected, weighed, and individually suspended in $1 \mathrm{ml}$ of 1/4 Ringer's buffer (Merck) supplemented with $0.02 \%$ diethyldithiocarbamic acid (DIECA, antioxidant) (Arcos Organics) in $15 \mathrm{ml}$ Falcon tubes. Each sample was crushed with a sterile, stainless steel manual homogenizer (Bionovo), and $100 \mu \mathrm{l}$ of serial dilutions were plated in duplicate on TSA plates supplemented with $100 \mu \mathrm{g} \mathrm{ml}^{-1}$ ampicillin and incubated for 24 to $48 \mathrm{~h}$ at $28^{\circ} \mathrm{C}$ before GFP-positive colonies were counted. The experiment was repeated independently once and the results were averaged.

Inoculation of in vitro-grown $S$. dulcamara plants with $D$. solani IPO2254 to study systemic colonization initiated from inoculated leaves. Estimation of IPO2254 inoculum used for infection of leaves. Prior to other experiments, we assessed (1) the D. solani IPO2254 inoculum on the tip of forceps used for plant inoculation and (2) the bacterial inoculum on the leaf after the leaf was mechanically wounded and infected with IPO2254. For this, the tip of the forceps was dipped in $10^{7} \mathrm{cfu} \mathrm{ml}^{-1}$ IPO2254 suspension in 1/4 Ringer's buffer (Merck) and immediately rinsed in $1 \mathrm{ml}$ of $1 / 4$ Ringer's buffer for $5 \mathrm{~s}$, serially diluted in the same buffer. Then, $100 \mu \mathrm{l}$ was plated on TSA supplemented with $100 \mu \mathrm{g} \mathrm{ml}^{-1}$ of ampicillin and incubated at $28^{\circ} \mathrm{C}$ for $48 \mathrm{~h}$. GFP-positive bacterial colonies were counted. The entire procedure was repeated six times for each of three independently prepared bacterial solutions $(n=18)$. Each time before sample collection, the forceps were sterilized with $70 \%$ ethanol, flamed, and cooled before being reused. Similarly, the 2-weekold in vitro-cultured $S$. dulcamara leaves (10 leaves in triplicate, $n=30$ ) were inoculated with IPO2254 suspension using the forceps (as described above). Each wounded leaf was immediately transferred to a 1.5-ml Eppendorf tube and macerated in $1 \mathrm{ml}$ of 1/4 Ringer's buffer with a sterile, manual homogenizer (Bionovo). The obtained suspensions were serially diluted and $100 \mu$ l duplicates were plated on TSA supplemented with $100 \mu \mathrm{g} \mathrm{ml}^{-1}$ of ampicillin, and incubated in $28^{\circ} \mathrm{C}$ for $48 \mathrm{~h}$ before counting the GFP-positive bacterial colonies.

Inoculation of S. dulcamara leaves. Two-week-old S. dulcamara plants, grown individually in De Wit culture tubes as described above, were used. One leaf, taken from the second or third pair of leaves, was pinched with the tip of the forceps $\left(0.4 \mathrm{~cm}^{2}\right)$ dipped in the IPO2254 suspension of $10^{7} \mathrm{cfu} \mathrm{ml}^{-1}$ in 1/4 Ringer's buffer as described above, without removing the plants from culture tubes and/or destroying the root system, giving a $\sim 1 \mathrm{~cm}$ long wound. Each experiment consisted of 28 plants: six inoculated plants and one negative control plant, that were sampled 3, 5, 7, and 10 dpi for the isolation of bacteria and colony counting as described above. The experiment was repeated independently once with the same setup.

Symptom development in vitro-grown plants after leaf inoculation. Plants with inoculated leaves were visually inspected 3, 10, and 14 dpi for symptom development including wilting, typical blackleg-like symptoms, stem desiccation, and/or plant death. Plant height, from the surface of the agar medium to the plant's tip, was determined at each time point.

Microscopy observations of $S$. dulcamara in vitro-grown plants infected with GFP-tagged $D$. solani IPO2254. In vitro plants inoculated at stem base or leaf with IPO2254 were randomly collected for microscopy analyses $14 \mathrm{dpi}$. The haulm and the leaves were removed from the De Wit culture tubes and cleaned of the agarmedium residues using sterile water. The stems were cut into $0.5-\mathrm{mm}$ slices and 0.5 to $1 \mathrm{~cm}$ pieces both crosswise and lengthwise. The leaves and roots were detached from the stems. At least 10 individual leaves, stems, and roots collected from at least 10 individual plants per experiment, together with uninoculated (control) samples, were used for microscopy studies. All tissues were embedded in PT agar medium (melted and cooled to $55^{\circ} \mathrm{C}$ ) (Burr and Schroth 1977), supplemented with $100 \mu \mathrm{g} \mathrm{ml}^{-1}$ ampicillin, in Petri dishes, and incubated for $48 \mathrm{~h}$ at $28^{\circ} \mathrm{C}$ (Czajkowski et al. 2010b). GFP-positive bacterial microcolonies were visualized at $495 \mathrm{~nm}$ blue light under Leica MZ10 F stereomicroscope UV imaging with an ET GFP filter and Leica DFC450C camera system as previously described (Czajkowski et al. 2010b).

Population dynamics of $D$. solani IPO2254 on S. dulcamara adaxial leaf surface in vitro. Two-week-old and $\sim 10 \mathrm{~cm}$ high S. dulcamara seedlings were transplanted individually to 0.25 -liter plastic pots filled with potting compost (COMPO SANA Universal Potting Compost, Compo) and kept in a growth chamber at $22^{\circ} \mathrm{C}$ and 16/8 h (day/night) photoperiod (white cool fluorescent light, Philips, TLD $58 \mathrm{~W} / 84 \mathrm{o}, 30$ to $35 \mu \mathrm{mol} \mathrm{m} \mathrm{m}^{-2} \mathrm{~s}^{-1}$ ) and $80 \%$ relative humidity (RH) for rooting and shoot development. After 2 weeks, S. dulcamara leaves (third to sixth from the shoot tip) were detached from the plant. Two milliliters of IPO2254 suspension adjusted to $10^{8} \mathrm{cfu} \mathrm{ml}^{-1}$ in sterile Ringer's buffer (Merck) was sprayed on the 
adaxial surface of each leaf using a manual sprayer. Sprayed leaves were dried under the air flow and placed adaxial side up on $0.5 \%$ water agar (Oxoid) in square plastic Petri dishes $(100 \times 100 \mathrm{~mm}$, Sarstedt). As control, sterile Ringer's buffer was used. The leaves were left to dry under the laminar flow, then transferred to the Petri dishes and kept in the growth chamber as described above. Samples were collected at $0,1,7$, and 14 days and assayed for the presence of D. solani IPO2254. At each time point, five randomly chosen leaves were collected from five randomly chosen Petri dishes and separately shaken in $20 \mathrm{ml}$ of Ringer's buffer in $50 \mathrm{ml}$ Falcon tubes (Sarstedt) at $50 \mathrm{rpm}$ at room temperature, each for $30 \mathrm{~min}$, to remove bacterial cells from the leaf surface. The washings were serially diluted in Ringer's buffer, and $100 \mu \mathrm{l}$ taken from the $10 \times$ and $100 \times$ diluted samples were plated in duplicates on TSA containing $100 \mu \mathrm{g} \mathrm{ml}^{-1}$ ampicillin to select for GFP-positive colonies and $100 \mu \mathrm{g} \mathrm{ml}^{-1}$ cycloheximide (Sigma) to prevent fungal growth before incubation. The plates were then incubated at $28^{\circ} \mathrm{C}$ and GPF-positive colonies were counted. The experiment was repeated once with the same setup and the results were averaged.

Growth of $S$. dulcamara plants in potting compost following stem-inoculation with $D$. solani IPO2254. Replicated experiments were performed in March 2017. S. dulcamara plants derived from apical meristems of culture tube-grown plants were collected and grown in individual 0.5 -liter plastic pots in potting compost and incubated as described above for 14 days prior to inoculation with the bacteria. Plants were inoculated ( $n=10$ per experiment) as follows: $0.5 \mathrm{~cm}$ long transverse cut was made at 30 degrees on each stem $5 \mathrm{~cm}$ from the stem base; $10 \mu \mathrm{l}$ (final concentration per inoculation point $10^{5} \mathrm{cfu}$ ) of the IPO2254 suspension in 1/4 Ringer's buffer was applied into the wound. As a control, plants were inoculated with $10 \mu l$ of 1/4 Ringer's buffer. After inoculation, the wound was covered in Parafilm (Parafilm M All-Purpose Laboratory Film, Bemis, WI) to protect it from desiccation. As with in vitro plants, S. dulcamara plants were visually inspected 14 and 30 dpi for infection development and were assessed for wilting, blackleg-like symptoms, stem desiccation, and plant death. Samples $(n=5)$ were collected at 14 and 30 dpi. For this, a 1.5 to $2 \mathrm{~cm}$ long stem fragment per plant was cut out $5 \mathrm{~cm}$ above the inoculation site and macerated in $1 \mathrm{ml}$ of 1/4 Ringer's buffer supplemented with DIECA (Sigma), using a sterile manual homogenizer (Bionovo). Duplications of $100 \mu \mathrm{l}$ of undiluted macerate were plated on TSA containing $100 \mathrm{mg} \mathrm{liter}^{-1}$ ampicillin and $100 \mathrm{mg} \mathrm{liter}^{-1}$ cycloheximide and incubated at $28^{\circ} \mathrm{C}$ for $48 \mathrm{~h}$ to allow the growth of GFP-tagged D. solani IPO2222. The experiment was repeated once with the same setup.

Statistical analysis. Bacterial count data were analyzed by ordinary linear regression using the statistical software package GenStat (Payne et al. 2007). To achieve the approximate normality, data were $\log$ transformed after adding value 1 to avoid taking logs of zero. Results were considered to be significant at $P=0.05$ and pair-wise differences were obtained using the $t$ test. Data were analyzed according to the experimental design in which two replicated experiments were done at each time point with treatments of replicated plants. The adopted linear model was a complete block design with replicates as complete blocks, main effects analyzed for time and treatment and the two-way interaction between time and treatment. Normal distribution was assumed for plant height and weight.

\section{Results}

Systemic colonization of in vitro $S$. dulcamara plants initiated at stem base and roots. Two independent experiments were conducted in June and July 2016. In each experiment, 20 plants per treatment were used and plant fitness and disease progression in plants inoculated with GFP-tagged D. solani IPO2222 (IPO2254) were investigated.

Fitness of $\mathrm{S}$. dulcamara plants and disease development.

Treatment A. No visible symptoms were observed in S. dulcamara plants inoculated with sterile 1/4 Ringer's buffer (negative control) during the entire course of both experiments and at $14 \mathrm{dpi}$ (end point). The average height and the average fresh weight were $7.73 \mathrm{~cm}$ and $151 \mathrm{mg}$, respectively (Fig. 1).
Treatments $B, C$, and $D$. General observations: in all treatments of S. dulcamara plants inoculated with $D$. solani IPO2254, five classes of symptoms were recorded (Fig. 1): (1) root colonization identified by a distinct turbidity of the MS medium around the roots, starting from the site of the inoculation and spreading down the roots; (2) embrowning of roots identified as a change of color from white/yellowish to brown/ black; (3) blackleg-like symptoms - blackening and soft rotting of the stem above and below the inoculation point; (4) wilting and yellowing of leaves; and finally (5) plant death when the haulm rotted extensively, the stem collapsed, and the plant parts were difficult to distinguish from one another (Fig. 1). Additionally, inoculation of plants with IPO2254 resulted in the reduction of plant fitness manifested by a decrease in average height and weight of plants in comparison with the plants inoculated with Ringer's buffer only (negative control, Treatment $A$ ).

Treatment $B$. At 14 dpi in plants inoculated with $10^{4} \mathrm{cfu} \mathrm{ml}^{-1}$ of IPO2254 symptoms included root colonization and embrowning, blackleg-like symptoms, and wilting and yellowing of leaves. These symptoms appeared after inoculation and progressed with time in both experiments. Root colonization could be observed as early as 2 dpi. Disease symptoms were observed in 87 and 100\% plants in the first and the second experiment, respectively. In both experiments, the height and fresh weight of plants at 14 dpi were, on average, $5.82 \mathrm{~cm}$ and $68 \mathrm{mg}$, respectively.

Treatment $C$. In plants inoculated with $10^{6} \mathrm{cfu} \mathrm{ml}^{-1}$ of $D$. solani at $14 \mathrm{dpi}$, all five types of symptoms were observed including plant death. Blackleg-like symptoms were observed in 93 and $100 \%$ plants in the first and second experiment, respectively. In both experiments at $14 \mathrm{dpi}$, the height and fresh weight of plants were, on average, $5.31 \mathrm{~cm}$ and $84 \mathrm{mg}$, respectively.

Treatment $D$. In plants inoculated with $10^{8} \mathrm{cfu} \mathrm{m}^{-1}$ of $D$. solani at $14 \mathrm{dpi}$, all five types of infection symptoms were observed as in treatment C. Interestingly, despite the higher inoculum than in treatments $\mathrm{B}$ and C, only 80 and $87 \%$ of plants showed disease symptoms in the first and second experiments, respectively. In both experiments at $14 \mathrm{dpi}$, the height and fresh weight of plants were, on average, $5.26 \mathrm{~cm}$ and average $45 \mathrm{mg}$, respectively.

Overall, at $14 \mathrm{dpi}$, plants inoculated with IPO2254 were on average shorter in all three treatments (treatments B, C, and D) by 25,31 , and $32 \%$, respectively, when compared with control plants (treatment A).

IPO2254 populations in $\mathrm{S}$. dulcamara haulms The number of bacteria present in plant haulms after stem base inoculation was evaluated 3, 7, 10, and $14 \mathrm{dpi}$ for each of the three inocula used in treatments B, C, and D of D. solani IPO2254 (Fig. 2). The values differed widely per plant and per treatment, but overall were not statistically different between replicated experiments 1 and 2, therefore the data were analyzed together (Figs. 2 and 3). Regardless of the initial inoculum used, all three treatments yielded symptomatic systemic colonization. In all treatments at $3 \mathrm{dpi}$, bacterial populations were high with an average of $10^{6}$ to $10^{7} \mathrm{cfu} \mathrm{g}^{-1}$ of haulms. No further increase in IPO2254 number was recorded at 7 and 10 dpi but at the end of experiment ( $14 \mathrm{dpi}$ ), the bacterial populations reached $10^{7}$ to $10^{9}$ $\mathrm{cfu}^{-1}$ of haulm tissue. No GFP-positive, ampicillin-resistant colonies were found in any of the samples taken from plants inoculated with sterile 1/4 Ringer's buffer (negative control - treatment A) in the entire course of both experiments.

Systemic colonization of $S$. dulcamara plants initiated at leaves. Two replicated experiments were conducted in January and February 2017. In each experiment, 28 plants were analyzed, with six plants inoculated with GFP-tagged $D$. solani per treatment and time point, and one control plant. Plant fitness and disease progression in plants inoculated with IPO2254 were monitored.

Determination of IPO2254 inoculum load delivered by the forceps method. The number of bacteria present on the tip of the forceps dipped in D. solani IPO2254 suspension $\left(10^{7} \mathrm{cfu} \mathrm{\textrm {ml } ^ { - 1 } )}\right.$ in Ringer's buffer was $10^{6} \mathrm{cfu}(n=18)$ on average, which resulted in $10^{5} \mathrm{D}$. solani cfu per infected leaf $(n=10)$.

Fitness of S. dulcamara plants and disease development after leaf infection. No statistically important differences between experiments 1 and 2 were found, and therefore the data were analyzed together. As with the stem base-inoculated in vitro plants, five classes of 
symptoms were also observed in plants that were leaf-inoculated with D. solani using forceps (Fig. 4): (1) colonization of roots, (2) roots embrowning, (4) wilting, and (5) full plant maceration leading to plant death. In comparison with the root-initiated colonization, no plant developed blackleg-like symptoms (3); however, an additional class of symptoms was determined, namely (4a) maceration of the inoculated leaf (Fig. 1). After 3 dpi, the only symptom assessed in $30 \%$ of the $S$. dulcamara plants was maceration of the first inoculated leaf. All five classes of symptoms were observed after 14 dpi (end point); the most abundant were the wilting of the haulms and maceration of the inoculated leaf, which were observed in $70 \%$ of plants in both experiments. Fifteen percent of symptomatic plants were fully macerated at the end point of the experiment. In total, after $14 \mathrm{dpi}, 80 \%$ of plants developed at least one of the five classes of symptoms (Fig. 4). At $14 \mathrm{dpi}$, the height of the plants inoculated with IPO2254 at leaf was on average $13 \%$ lower than in case of the control plants. In the course of both experiments, the control plants, inoculated with sterile $1 / 4$ Ringer's buffer, did not exhibit any disease symptoms. The wounded leaves remained green with some minor necrosis due to bruising. The average height of the control plants after 14 dpi was $6.9 \mathrm{~cm}$.

IPO2254 populations in S. dulcamara haulms. Plant haulms collected after 3, 5, 7, and 10 dpi revealed the presence of IPO2254 in all S. dulcamara plants following leaf inoculation. The D. solani populations were stable, with an average of $10^{7}$ to $10^{8} \mathrm{cfu} \mathrm{g}^{-1}$ of haulms during the entire course of both experiments (Fig. 5).

Microscopy observations of $D$. solani IPO2254 in inoculated S. dulcamara plants. In the stem base- and leaf-inoculated plants, at 14 dpi, GFP-positive microcolonies were found on and inside the $S$. dulcamara stems and roots that were collected, embedded in PT medium, and enriched for bacterial presence (Fig. 6). The fluorescence signal was not detected in leaves of the inoculated plants, but was predominantly localized in the stem and root vascular tissues as well as on the surface of the stem central hollow (outside the stem vascular system). In roots, the GFP signal was found both inside in the vascular tissue and on the outer surface (Fig. 6). The primarily inoculated leaves of the leaf-inoculated plants were not investigated
(1)

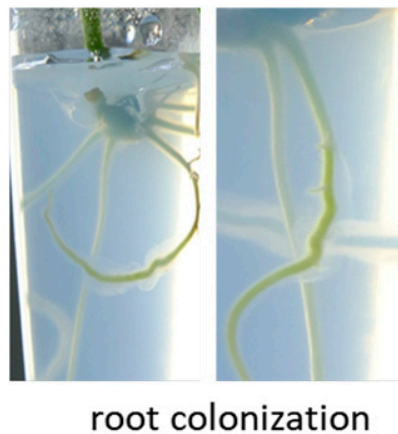

(4)

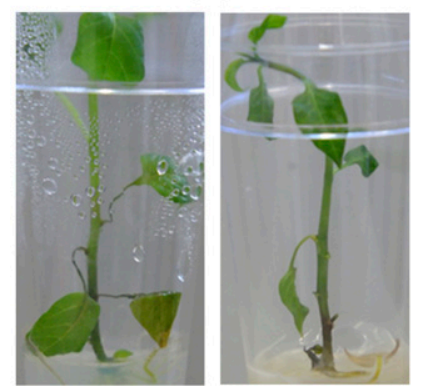

wilting and yellowing of leaves
(2)

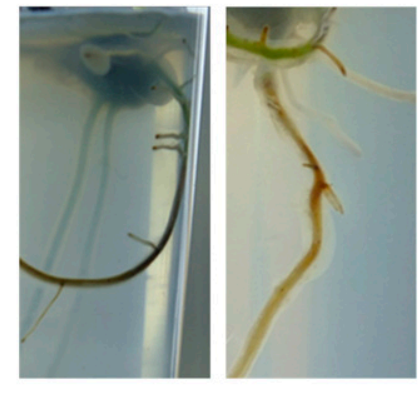

root embrowning

(4a)

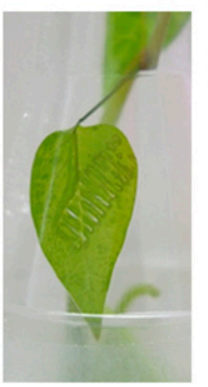

maceration of primarily inoculated leaf
(3)

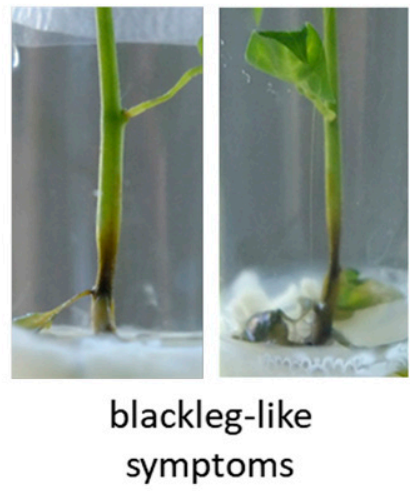

(5)

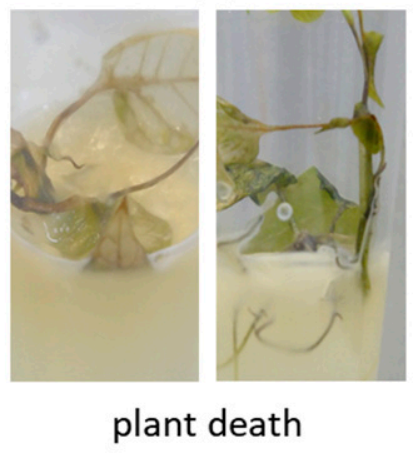

(control)

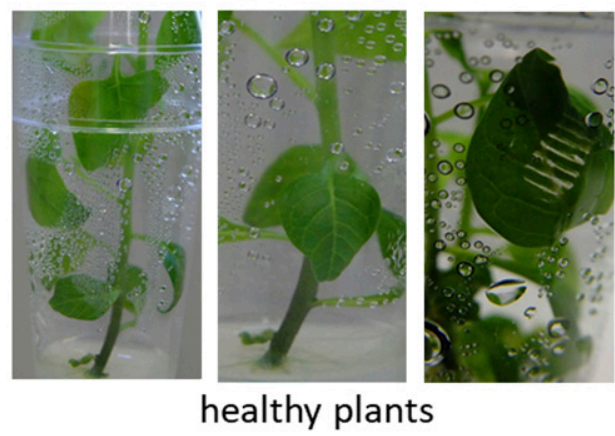

Fig. 1. Classes of symptoms observed in in vitro Solanum dulcamara plants after (1) stem base and root and (2) leaf inoculations with Dickeya solani IPO2254. Disease severity was assigned to five classes (categories): class (1) - root colonization identified as increase of turbidity of the MS medium around roots; class (2) - root embrowning identified as a change in root surface color from white/yellow to brown/black; class (3) - blackleg-like symptoms, blackening and softening of the stem above and below stem base; class (4) wilting and yellowing of leaves; class (4a) - maceration of the inoculated leaf, (on leaf-inoculated plants only); class (5) - plant death with the symptoms of heavy rot of haulms. 
microscopically due to extensive decomposition of plant tissue. D. solani IPO2254 was found in all treatments except for the negative control plants (treatment A).

Survival of $D$. solani IPO2254 on the surface of detached S. dulcamara leaves. In replicated experiments, survival of IPO2254 on the adaxial surface of detached S. dulcamara leaves was monitored weekly over a period of 14 days (Fig. 7). The number of bacteria differed widely per plant and per treatment, but was not statistically significant different between experiments 1 and 2; therefore, these data were analyzed together. In both experiments, at $0 \mathrm{dpi}$, average populations of $10^{6} \mathrm{cfu}$ per leaf were found and at $1 \mathrm{dpi}$ these populations remained unaltered. No further statistically significant changes in D. solani populations at 7 and $14 \mathrm{dpi}$ in comparison with $1 \mathrm{dpi}$ were observed in the course of both experiments (Fig. 7). No GFP-tagged ampicillin resistant bacteria were found on leaves not inoculated with IPO2254 (negative control) in both experiments.

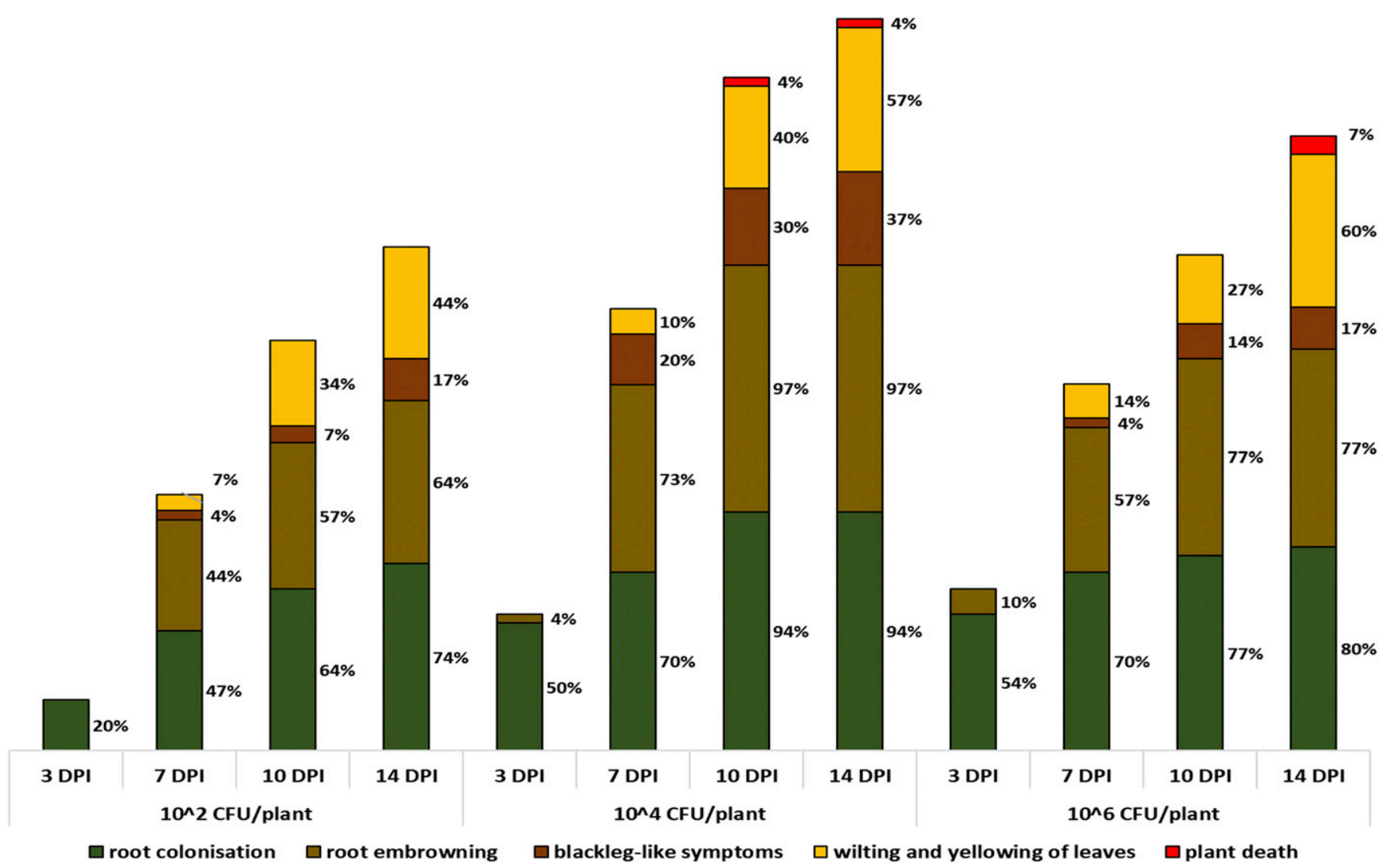

Fig. 2. Disease symptoms observed after inoculation of stem and roots of Solanum dulcamara plants with Dickeya solani IPO2254, shown as percentage of affected plants. Plants were grown in vitro under growth chamber conditions at $22^{\circ} \mathrm{C}$ and $16 / 8 \mathrm{~h}$ photoperiod. In replicated experiments, 120 plants were used (60 plants per experiment) subjected to three inoculation levels, on 20 plants each: $10^{2}, 10^{4}$, and $10^{6}$ IPO2254 cfu per plant. Symptoms were evaluated at four time points: $3,7,10$, and 14 days post inoculation. Percentages do not sum up to 100 as often several symptoms per plant were observed.

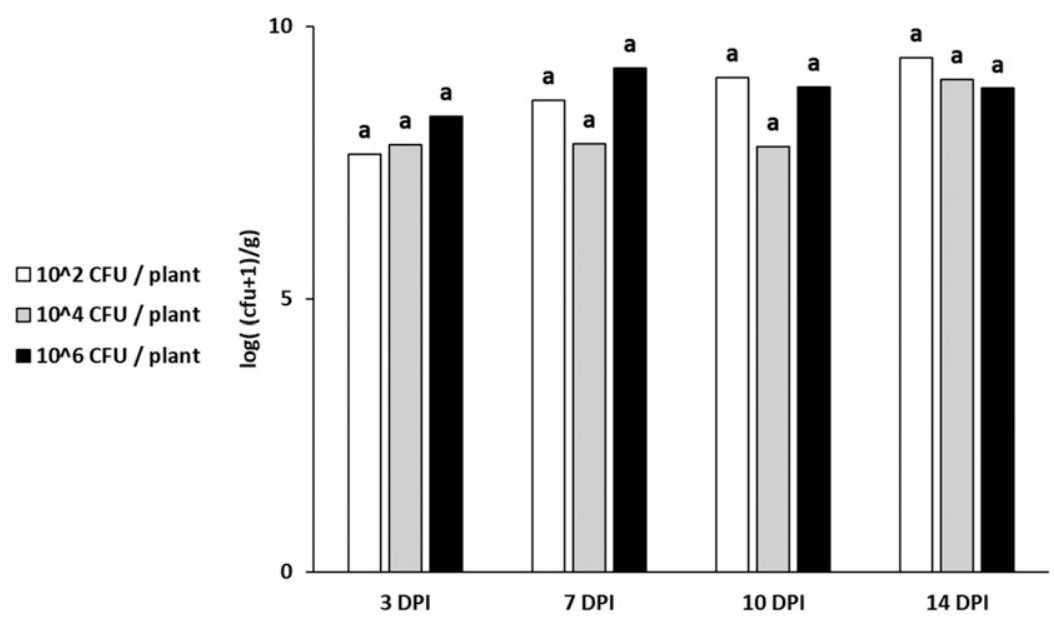

Fig. 3. Dickeya solani populations in culture tube-grown Solanum dulcamara haulms after stem base and root inoculations with IPO2254. Plants were grown in culture tubes under growth chamber conditions at $22^{\circ} \mathrm{C}$ and $16 / 8 \mathrm{~h}$ photoperiod. In replicated experiments, 120 plants were used ( 60 plants per experiment) divided to three inoculation levels, on 20 plants each, with IPO2254: $10^{2}, 10^{4}$, and $10^{6} \mathrm{CFU} /$ plant. At each time point $(3,7,10$, and 14 days post inoculation), five samples per treatment were analyzed. Haulms were collected and weighed, and haulm extracts in $1 / 4$ Ringer's buffer (Merck) were plated on tryptone soya agar plates supplemented with $100 \mu \mathrm{g} \mathrm{m} l^{-1}$ ampicillin and incubated at $28^{\circ} \mathrm{C}$ for 24 to $48 \mathrm{~h}$. GFP-positive, ampicillin-resistant bacterial colonies were counted. 
Presence of $D$. solani IPO2254 on $S$. dulcamara after inoculation of plants grown in potting compost. No ampicillin-resistant, GFP-positive bacterial colonies were found in samples of IPO2254inoculated plants taken at 14 dpi (data not shown). Among 20 plants tested in both replicates ( $n=10$ per experiment) after $30 \mathrm{dpi}$, the GFP-tagged bacteria were detected in eight stems (four in experiment 1 with bacterial densities of $7 \times 10^{3}, 5 \times 10^{1}, 3.5 \times 10^{4}$, and $2.6 \times 10^{4}$ per gram of plant tissue and four in experiment 2 with bacterial densities of $3.3 \times 10^{4}, 2.7 \times 10^{4}, 3 \times 10^{4}$, and $7.9 \times 10^{3}$ per gram of plant tissue). Number of bacteria differed widely between plants, ranging from $10^{1}$ to $10^{4} \mathrm{cfu} \mathrm{g}^{-1}$ of stem tissue. None of the plants inoculated with IPO2254 revealed any visible disease symptoms during the course of both experiments. Control plants inoculated with Ringer's buffer remained symptomless, and no GFP-tagged bacteria were isolated from the stems at any time point.

\section{Discussion}

In this study, we have shown for the first time that infection of culture tube-grown $S$. dulcamara with D. solani can result in the development of disease symptoms, similar to those observed on in vitro

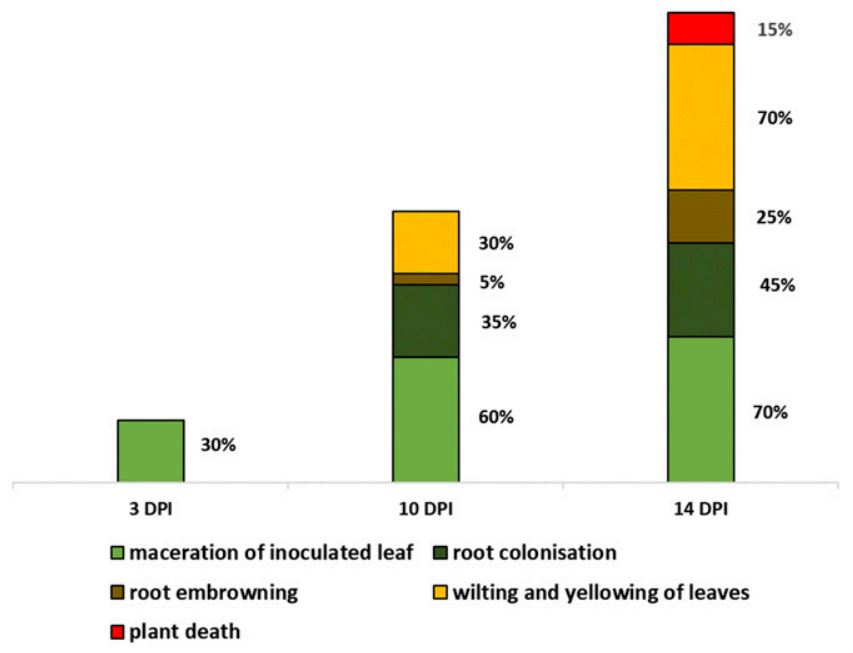

Fig. 4. Symptoms observed after inoculation of leaves of culture tube-grown Solanum dulcamara plants with Dickeya solani IPO2254, shown as percentage of affected plants. Plants were grown in a growth chamber at $22^{\circ} \mathrm{C}$ and $16 / 8 \mathrm{~h}$ photoperiod. In replicated experiments, 56 plants were used ( 28 plant per experiment). Symptoms were evaluated at three time points: 3,10 , and 14 days post inoculation. Percentages do not sum up to 100 as often several symptoms per plant were observed.

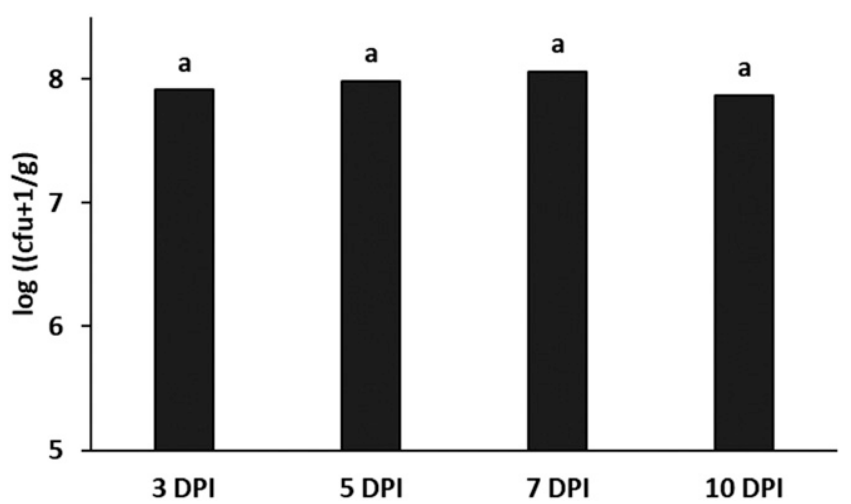

Fig. 5. Dickeya solani populations in culture tube-grown Solanum dulcamara haulms after leaf inoculation with IPO2254. Plants were grown in a growth chamber at $22^{\circ} \mathrm{C}$ and $16 / 8 \mathrm{~h}$ photoperiod. In replicated experiments, 56 plants were used (28 plant per experiment). At each time point ( $3,5,7$, and 10 days post inoculation), six plants per treatment were sampled together with one control plant. Haulms were collected and weighed, and haulm extracts, prepared in 1/4 Ringer's buffer (Merck), were plated on tryptone soya agar plates supplemented with $100 \mu \mathrm{g} \mathrm{ml} l^{-1}$ ampicillin and incubated at $28^{\circ} \mathrm{C}$ for 24 to $48 \mathrm{~h}$. GFP-positive, ampicillin-resistant bacterial colonies were counted. cultivated potato ( $S$. tuberosum), and in systemic colonization of the plants. Despite the fact that the pectinolytic bacteria have been repeatedly reported on $S$. dulcamara grown in natural habitats (Fikowicz-Krosko et al. 2017; Olsson 1985; Toth et al. 2011), no extensive studies have been done to assess the role of bittersweet nightshade in the spread and survival of pectinolytic bacteria in nature. Likewise, no detailed studies have been conducted to evaluate the
A$$
\text { A }
$$

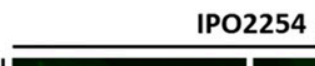

$\mid$

root
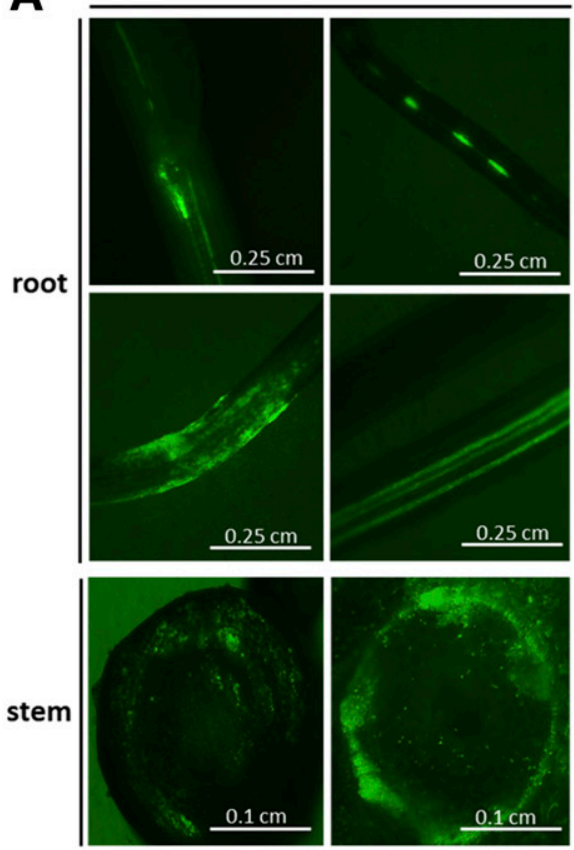

B

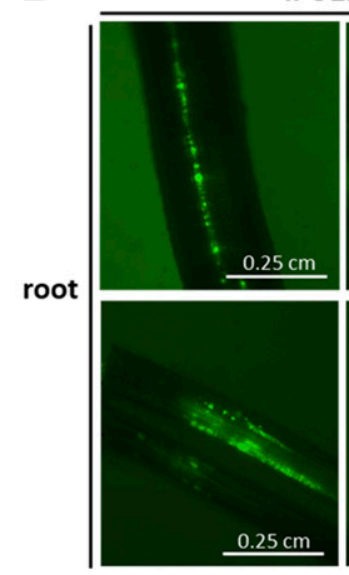

IP02254
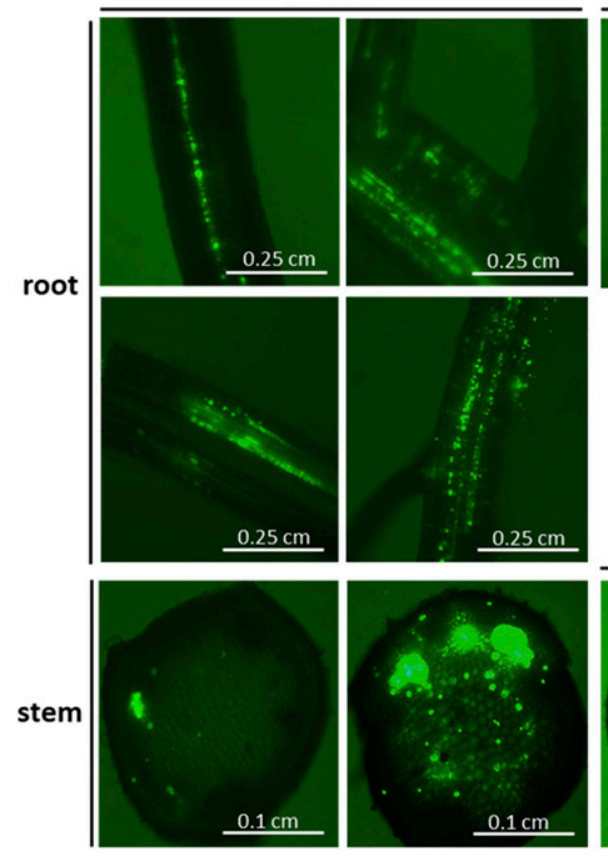

control

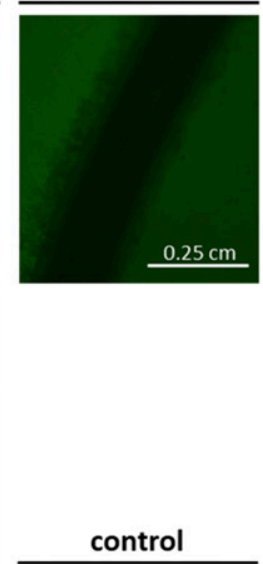

control

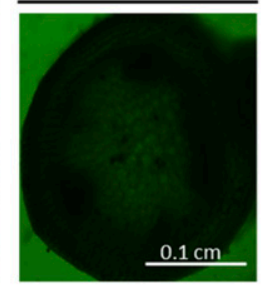

control
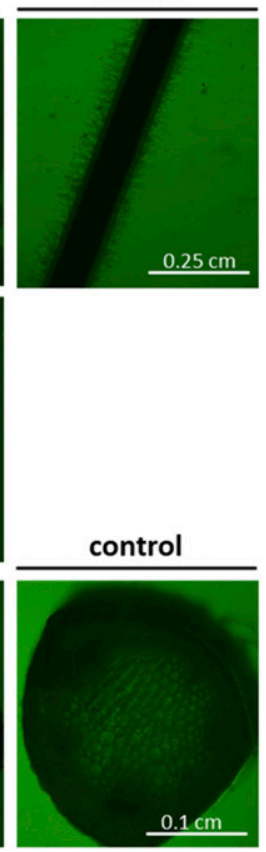

Fig. 6. Fluorescence microscopy of tissue culture Solanum dulcamara plants inoculated with IPO2254 at stem base and roots (A) and leaf (B). Samples of S. dulcamara roots and stems were collected 14 days post inoculation for microscopy observations and were embedded in the PT medium and incubated for $48 \mathrm{~h}$ at $28^{\circ} \mathrm{C}$ to enrich bacterial cultures and GFP signal inside plant tissues. At least 10 individual random stem and root samples collected from at least 10 individual plants per experiment were used for microscopy observation at magnification of $2.5 \times$ to 10x. GFP signal was visualized at $495 \mathrm{~nm}$ blue light under Leica MZ10 F stereomicroscope UV imaging with an ET GFP filter and Leica DFC450C camera system. Representative images are shown. 
routes by which $D$. solani invades $S$. dulcamara. A better understanding of $D$. solani virulence and symptom expression on $S$. dulcamara can lead to identification of new critical target points leading to successful reduction of the spread of pectinolytic bacteria in the environment and development of appropriate procedures involving weed control. Furthermore, this study shows for the first time that the axenically grown (weed) plants can be used successfully to study the effect of alternative hosting of SRE. Once introduced to culture tubes, these plants are grown under strictly controlled conditions and therefore the results are highly reproducible. Similarly, as it was reported previously, the pectinolytic bacteria are unable to grow in in vitro culture media without the presence of the host plants (Leifert and Waites 1992). Therefore, the possibility of obtaining false-positive colonization and infection results in the assay are minimal. Consequently, this may serve as a method of choice for the first screening of other wild plants as Pectobacterium spp. and Dickeya spp. hosts. This proposed screening method can be easily scaled up if required. However, it must be pointed out here that symptoms observed in in vitro grown plants does not necessary reflect the natural infection occurring under field conditions.

A systemic colonization of potato plants by fluorescently labeled Pectobacterium spp. and Dickeya spp. has been discussed in several studies (Czajkowski et al. 2010a; Golan et al. 2010; Kubheka et al. 2013), but the colonization of $S$. dulcamara by a GFP-tagged $D$. solani has not. Using a GFP-tagged strain and two routes of inoculation ([1] stem base together with roots and [2] leaves), a rapid colonization of in vitro $S$. dulcamara was visualized by dilution plating and fluorescent microscopy.

The infection of $S$. dulcamara plants grown in tissue culture with D. solani was rapid. The first symptoms of root colonization after pipetting the bacterial culture in the interspace between the agar medium and the stem base were observed 2 days after the inoculation. This was comparable with symptom development in the roots of in vitro potato plants in our earlier studies (Czajkowski et al. 2015). Similarly, after leaf inoculation, the first symptoms were recorded in a relatively short time ( $3 \mathrm{dpi}$ ) but leaves had to be wounded mechanically to allow bacteria to enter the leaf tissue. In the detached leaf assay, non-wounded $S$. dulcamara leaves did not exhibit any disease symptoms when sprayed with the bacterial inoculum on the adaxial side of leaves. This is also in agreement with our former studies on the colonization of potato leaves by $D$. solani, where the use of a carborundum powder to abrade the leaf surface was required for the bacteria to penetrate plant tissue (Czajkowski et al. 2010a). Overall, our observations indicate that $D$. solani, under in vitro conditions, is highly virulent not only in potato as was reported previously (Toth et al. 2011), but probably also in closely related plant species such as S. dulcamara. In our former studies, $S$. tuberosum plants grown under the same in vitro conditions and inoculated with $D$. solani IPO2254 via application of bacteria into the interspace between stem base and agar medium, expressed severe disease symptoms including typical blackleg and plant death in the majority of plants (Czajkowski et al. 2015).

D. solani could penetrate intact roots of the in vitro grown plants, which may indicate that it could behave alike under natural conditions, although this still needs to be experimentally confirmed. In potato fields, $D$. solani can be released from a rotting mother tuber or from an infected root system and migrate with water in the soil up to a distance of $10 \mathrm{~m}$ (Graham and Harper 1967), far enough to find a new host. A chronic infestation of soil can take place during rainfall if high numbers of bacteria are released into the soil from decaying tubers or blackleg-affected stems (Pérombelon 1982). Similarly, in our study, D. solani could survive on the leaf surface for at least 14 days, from where it could further spread to other plants via wind blow or with rain aerosols.

A systemic colonization of plants was recorded regardless of the inoculation routes chosen, indicating that it cannot be excluded that $S$. dulcamara may also be infected in nature with $D$. solani via an air-, water-, and/or soilborne inoculum. D. solani is not considered under normal circumstances to be a soilborne nor airborne pathogen, but in fields where infected crops are grown or drainage water from such fields is used in cultivation areas, the bacteria might be transferred with air or water. It is well established that under field conditions, infected potato tubers release SRE into the soil (Burr and Schroth 1977; Czajkowski et al. 2010b; Pérombelon and Hyman 1989; Powelson and Apple 1984), where the bacteria may spread and colonize roots of other host and nonhost plants, including S. dulcamara. Similarly, an aerial infection may occur from neighboring fields as bacteria of the Dickeya spp. may be transferred by wind, rain water, or aerosols to plants growing close to infected potato fields (Graham and Harrison 1975; Pérombelon 2002; Pérombelon et al. 1979). Moreover, $S$. dulcamara may get infected via insect transmission of bacteria (Grenier et al. 2006; Kloepper et al. 1981).

A systemic infection of stem base/root-inoculated in vitro $S$. dulcamara plants, together with the emergence of disease symptoms, can take place under a range of bacterial inocula. This suggests that under favorable conditions, the infection of a secondary host under in vitro conditions can develop even with a very low level of inoculum, $\sim 100$ cfu per plant. Essentially, similar results were obtained for potato (Toth et al. 2011). Data concerning SRE populations on weeds under natural conditions is limited. Although it is probable that many varieties of weeds may harbor SRE (de Boer 2003), few, if any, would enable the bacteria to survive in a systemic infection that could lead to a disease development as shown in this study with $S$. dulcamara. These results highlight the potential of $S$. dulcamara and other Solanaceae weed plants as a reservoir for $D$. solani in the environment.

To date, only several reports have shown the presence of SRE on weeds growing in the vicinity of potato fields. Tsror et al. (2010) reported that Cyperus rotundus (nut grass) growing near potato fields in Israel may be latently infected by $D$. solani (Tsror et al. 2010). We have isolated $P$. carotovorum subsp. carotovorum from symptomless roots of $S$. dulcamara growing in a potato cultivation region in northern Poland (Fikowicz-Krosko et al. 2017). This indicates that weeds, especially if they grow near potato fields, may become a reservoir (alternative host) for Pectobacterium spp. and Dickeya spp. The sizes of SRE populations in and on weeds are usually small ( $\sim 10$ to 100 cells per plant as observed in our studies, unpublished data), but we can speculate that in the worst-case scenario, when a highly disease-susceptible potato cultivar was concerned and favorable weather conditions occur, this reservoir might be sufficient to support infection in potato crops.

The fact that $D$. solani does not cause disease development on S. dulcamara plants grown in potting compost is of rather minor importance. In contrast to the culture tube-grown plants, S. dulcamara grown in potting compost in a growth chamber setup failed to develop disease symptoms after being inoculated with $10^{5} \mathrm{cfu}$ per plant

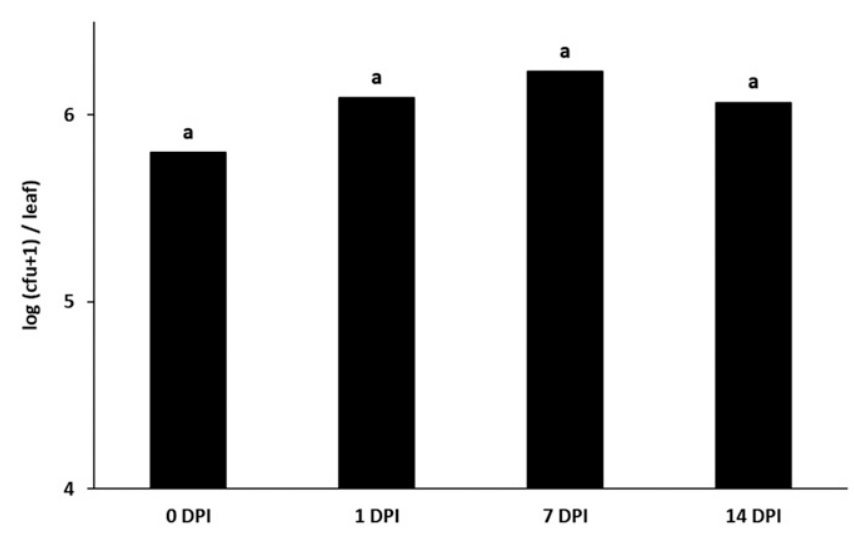

Fig. 7. Population dynamics of Dickeya solani IPO2254 on adaxial surface of Solanum dulcamara leaves. In replicated experiments, 40 leaves (20 leaves per experiment) were sampled at four time points $(0,1,7$, and 14 days post inoculation [dpi]). At each sampling time, five leaves (third to sixth from the shoot terminal) were detached per plant, spray-inoculated with $2 \mathrm{ml}^{\circ} 10^{8} \mathrm{cfu} \mathrm{ml}^{-1} \mathrm{IPO} 2254$ bacterial suspension in $1 / 4$ Ringer's buffer, and incubated adaxial side up on $0.5 \%$ water agar in square plastic Petri dishes $(100 \times 100 \mathrm{~mm})$. At 0, 1, 7, and $14 \mathrm{dpi}$, five randomly chosen leaves from five randomly chosen Petri dishes were collected and individually shaken in $20 \mathrm{ml}$ Ringer's buffer in $50-\mathrm{ml}$ Falcon tubes at $50 \mathrm{rpm}$ at room temperature for $30 \mathrm{~min}$ to rinse bacterial cells off the leaf surface. The serially diluted washings were plated on tryptone soya agar plates supplemented with $100 \mu \mathrm{g} \mathrm{ml}-1$ ampicillin and incubated at $28^{\circ} \mathrm{C}$ for 24 to $48 \mathrm{~h}$ and GFPpositive, ampicillin-resistant bacterial colonies counted. 
by stem puncturing. It is likely that the in vitro plants, due to the applied growth method, were more susceptible to bacterial infection (Pierik 1997), or simply the presence of saprophytic microflora prevented $D$. solani proliferation and reaching a threshold level for virulence expression (Charkowski 2006). Then again, no symptoms caused by pectinolytic bacteria on field-grown S. dulcamara and other weeds like $C$. rotundus were described and all reported isolations were done from symptomless plant tissues. Likewise, D. dianthicola, bacteria closely related to $D$. solani, was found to infect $S$. dulcamara under glasshouse conditions, but the observed symptoms were only minor (Elphinstone 2008). This may indicate that, although Dickeya spp. and Pectobacterium spp. may systemically infect common weeds including S. dulcamara, the expression of disease symptoms is altered for an unknown reason.

It can also be that the soil-grown $S$. dulcamara plants were cultivated under conditions not promoting $D$. solani infections. However, $40 \%$ of these symptomless plants were systemically infected with IPO2254 populations in stems of $10^{1}$ to $10^{4} \mathrm{cfu} \mathrm{g}^{-1}$ plant tissue at 30 dpi. Similar populations of IPO2254 were found in stems of potato plants growing in soil infested with $10^{8} \mathrm{cfu} \mathrm{ml}^{-1}$ D. solani (Czajkowski et al. 2010b) or following an axial leaf inoculation with $10^{8} \mathrm{cfu} \mathrm{ml}^{-1} P$. carotovorum subsp. carotovorum of plants grown under greenhouse conditions (Rahimian and Mitchell 1984).

Microscopy observations of in vitro $S$. dulcamara tissues inoculated with GFP-tagged $D$. solani showed the same colonization pattern as observed in IPO2254-inoculated potato plants (Czajkowski et al. 2010a, b). In both cases, IPO2254 colonized the root pith tissue and stem xylem vessels. Although the knowledge on D. solani colonization patterns of weeds (including $S$. dulcamara) is limited, we can assume that in general it would be similar as for most known plant-associated bacteria (Alfano and Collmer 1996; Romantschuk 1992). The systemic colonization of S. dulcamara under natural conditions remains largely unknown and requires further studies.

In conclusion, our results suggest that $S$. dulcamara has a potential to be an important reservoir for SRE bacteria in the environment, facilitating Pectobacterium spp. and Dickeya spp. survival, hence playing an important role in the blackleg epidemiology. Further investigations are needed to evaluate the risk of a $S$. dulcamarapotato cross infection with SRE bacteria.

\section{Acknowledgments}

The work was financially supported by the National Science Center, Poland (Narodowe Centrum Nauki, Polska) via research grant SONATA 8 (2014/15/D/ NZ9/00605) to Robert Czajkowski. The authors would like to express their gratitude to Titti Mariani (Department of Molecular Plant Physiology, Radboud University, Nijmegen, the Netherlands) for providing $S$. dulcamara plants and cultivation protocols, Jan M. van der Wolf (Wageningen University and Research Centre, Plant Research International, Wageningen, The Netherlands) for providing the GFP-tagged D. solani IPO2254 strain, Michel Pérombelon (ex. SCRI, now The James Hutton Institute, Dundee, Scotland, U.K.), and Magdalena Rajewska (University of Gdansk, Poland) for their valuable comments on the manuscript and their editorial work.

\section{Literature Cited}

Alfano, J. R., and Collmer, A. 1996. Bacterial pathogens in plants: life up against the wall. Plant Cell Online 8:1683-1698.

Álvarez, B., Biosca, E. G., and López, M. M. 2010. On the life of Ralstonia solanacearum, a destructive bacterial plant pathogen. Pages 267-279 in: Current Research, Technology and Education Topics in Applied Microbiology and Microbial Biotechnology, Vol. 1. A. Mendez-Vilas, ed. Formatex Research Center, Badajoz, Spain.

Burr, T. J., and Schroth, M. N. 1977. Occurrence of soft-rot Erwinia spp. in soil and plant material. Phytopathology 67:1382-1387.

Charkowski, A. O. 2006. The soft rot Erwinia. Pages 423-505 in: Plant-Associated Bacteria. S. S. Gnanamanickam, ed. Springer, Dordrecht, The Netherlands.

Czajkowski, R., de Boer, W. J., van Veen, J. A., and van der Wolf, J. M. 2010a. Downward vascular translocation of a green fluorescent protein-tagged strain of Dickeya sp. (biovar 3) from stem and leaf inoculation sites on potato. Phytopathology 100:1128-1137.

Czajkowski, R., de Boer, W. J., Velvis, H., and van der Wolf, J. M. $2010 \mathrm{~b}$. Systemic colonization of potato plants by a soilborne, green fluorescent proteintagged strain of Dickeya sp. biovar 3. Phytopathology 100:134-142.

Czajkowski, R., Grabe, G. J., and van der Wolf, J. M. 2009. Distribution of Dickeya spp. and Pectobacterium carotovorum subsp. carotovorum in naturally infected seed potatoes. Eur. J. Plant Pathol. 125:263-275.
Czajkowski, R., van der Wolf, J. M., Krolicka, A., Ozymko, Z., Narajczyk, M. Kaczynska, N., and Lojkowska, E. 2015. Salicylic acid can reduce infection symptoms caused by Dickeya solani in tissue culture grown potato (Solanum tuberosum L.) plants. Eur. J. Plant Pathol. 141:545-558.

de Boer, S. H. 2003. Characterization of pectolytic Erwinias as highly sophisticated pathogens of plants. Eur. J. Plant Pathol. 109:893-899.

Elphinstone, J. G. 2008. Revised investigation of Erwinia chrysanthemi (Dickeya dianthicola and other Dickeya spp.) able to infect potatoes. Project Report 2008/7. Potato Council, Kenilworth, Warwickshire, U.K.

Elphinstone, J. G., and Pérombelon, M. C. M. 1986. Contamination of potatoes by Erwinia carotovora during grading. Plant Pathol. 35:25-33.

Elphinstone, J. G., Stanford, H. M., Stead, D. E. 1998. Detection of Ralstonia solanacearum in potato tubers, Solanum dulcamara and associated irrigation water. Pages 133-139 in: Bacterial Wilt Disease. P. Prior, C. Allen, and J. G. Elphinstone, eds. Springer, Berlin, Heidelberg, Germany.

Fikowicz-Krosko, J., Wszalek-Rozek, K., Smolarska, A., and Czajkowski, R. 2017. First report of isolation of soft rot Pectobacterium carotovorum subsp. carotovorum from symptomless bittersweet nightshade occurring in rural area of Poland. J. Plant Pathol. 99:287.

Flier, W. G., van den Bosch, G. B. M., and Turkensteen, L. J. 2003. Epidemiological importance of Solanum sisymbriifolium, S. nigrum and S. dulcamara as alternative hosts for Phytophthora infestans. Plant Pathol. 52:595-603.

Forcella, F., and Stephen, J. H. 1988. Patterns of weed migration in northwestern U.S.A. Weed Sci. 36:194-201. http://www.jstor.org/stable/4044869

Golan, A., Kerem, Z., Tun, O. M., Luzzatto, T., Lipsky, A., and Yedidia, I. 2010. Combining flow cytometry and $g f p$ reporter gene for quantitative evaluation of Pectobacterium carotovorum ssp. carotovorum in Ornithogalum dubium plantlets. J. Appl. Microbiol. 108:1136-1144.

Golas, T. M., Feron, R. M. C., van den Berg, R. G., van der Weerden, G. M., Mariani, C., and Allefs, J. J. H. M. 2010a. Genetic structure of European accessions of Solanum dulcamara L. (Solanaceae). Plant Syst. Evol. 285:103-110.

Golas, T. M., van der Weerden, G. M., van den Berg, R. G., Mariani, C., and Allefs, J. J. H. M. 2010b. Role of Solanum dulcamara L. in potato late blight epidemiology. Potato Res. 53:69-81.

Graham, D. C., and Harper, P. C. 1967. Potato blackleg and tuber soft rot. Scott. Agric. 48:68-74.

Graham, D. C., and Harrison, M. D. 1975. Potential spread of Erwinia spp. in aerosols. Phytopathology 65:739-741.

Grenier, A. M., Duport, G., Pagès, S., Condemine, G., and Rahbé, Y. 2006. The phytopathogen Dickeya dadantii (Erwinia chrysanthemi 3937) is a pathogen of the pea aphid. Appl. Environ. Microbiol. 72:1956-1965.

Kloepper, J. W., Brewer, J. W., and Harrison, M. D. 1981. Insect transmission of Erwinia carotovora var. carotovora and Erwinia carotovora var. atroseptica to potato plants in the field. Am. Potato J. 58:165-175.

Kubheka, G. C., Coutinho, T., Moleleki, N., and Moleleki, L. N. 2013. Colonisation patterns of a mCherry-tagged Pectobacterium carotovorum subsp. brasiliense strain in potato plants. Phytopathology 103:1268-1279.

Leifert, C., and Waites, W. M. 1992. Bacterial growth in plant tissue culture media. J. Appl. Bacteriol. 72:460-466.

Ma, B., Hibbing, M. E., Kim, H. S., Reedy, R. M., Yedidia, I., Breuer, J., Breuer, J., Glasner, J. D., Perna, N. T., Kelman, A., and Charkowski, A. O. 2007. Host range and molecular phylogenies of the soft rot enterobacterial genera Pectobacterium and Dickeya. Phytopathology 97:1150-1163.

Mansfield, J., Genin, S., Magori, S., Citovsky, V., Sriariyanum, M., Ronald, P., Dow, M., Verdier, V., Beer, S. V., Machado, M. A., Toth, I., Salmond, G., and Foster, G. D. 2012. Top 10 plant pathogenic bacteria in molecular plant pathology. Mol. Plant Pathol. 13:614-629.

Murashige, T., and Skoog, F. 1962. A revised medium for rapid growth and bioassays with tobacco tissue cultures. Physiol. Plant. 15:473-497.

Olsson, K. 1985. Detection of Erwinia spp. in some Swedish streams. Pages 45-46 in: Report of the International Conference on Potato Blackleg Disease, Roya Society of Edinburgh, 26-29 June 1984. D. C. Graham and M. D. Harrison, eds. Potato Marketing Board, Oxford, U.K.

Payne, R. W., Murray, D. A., Harding, S. A., Baird, D. B., and Soutar, D. M. 2007. GenStat for Windows (9th Edition) Introduction. VSN International Ltd, Hemel Hempstead, U.K.

Pegtel, D. M. 1985. Germination in populations of Solanum dulcamara L. from contrasting habitats. New Phytol. 100:671-679.

Pérombelon, M. C. M. 1982. The impaired host and soft rot bacteria. Pages 55-69 in: Phytopathogenic Prokaryotes. Academic Press, New York.

Pérombelon, M. C. M. 2000. Blackleg risk potential of seed potatoes determined by quantification of tuber contamination by the causal agent and Erwinia carotovora subsp. atroseptica: a critical review. EPPO Bull. 30:413-420.

Pérombelon, M. C. M. 2002. Potato diseases caused by soft rot Erwinias: an overview of pathogenesis. Plant Pathol. 51:1-12.

Pérombelon, M. C. M., Fox, R. A., and Lowe, R. 1979. Dispersion of Erwinia carotovora in aerosols produced by the pulverization of potato haulm prior to harvest. J. Phytopathol. 94:249-260.

Pérombelon, M. C. M., and Hyman, L. J. 1989. Survival of soft rot coliforms, Erwinia carotovora subsp. carotovora and E. carotovora subsp. atroseptica in soil in Scotland. J. Appl. Bacteriol. 66:95-106.

Pierik, R. L. M. 1997. In vitro culture of higher plants. Springer, Dordrecht, The Netherlands. 
Powelson, M. L., and Apple, J. D. 1984. Soil and seed tubers as sources of inoculum of Erwinia carotovora subsp. carotovora for stem soft rot of potatoes. Phytopathology 74:429-432.

Rahimian, M. K., and Mitchell, J. E. 1984. Population dynamics of Erwinia carotovora pv. carotovora in potato stems. Phytopathology 74:217-220.

Romantschuk, M. 1992. Attachment of plant pathogenic bacteria to plant surfaces. Annu. Rev. Phytopathol. 30:225-243.

Shah, F. A., Falloon, R. E., and Bulman, S. R. 2010. Nightshade weeds (Solanum spp.) confirmed as hosts of the potato pathogens Meloidogyne fallax and Spongospora subterranea f. sp. subterranea. Australas. Plant Pathol. 39:492-498.

Toth, I. K., van der Wolf, J. M., Saddler, G., Lojkowska, E., Hélias, V., Pirhonen, M., Tsror, L., and Elphinstone, J. G. 2011. Dickeya species: an emerging problem for potato production in Europe. Plant Pathol. 60:385-399.
Tsror, L., Lebiush, S., Erlich, O., Ben-Daniel, B., and van der Wolf, J. M. 2010. First report of latent infection of Cyperus rotundus caused by a biovar 3 Dickeya sp. (syn. Erwinia chrysanthemi) in Israel. New Dis. Rep. 22:14.

van der Wolf, J. M., Nijhuis, E. H., Kowalewska, M. J., Saddler, G. S., Parkinson, N., Elphinstone, J. G., Pritchard, L., Toth, I. K., Lojkowska, E., Potrykus, M., Waleron, M., de Vos, P., Cleenwerck, I., Pirhonen, M., Garlant, L., Hélias, V. Pothier, J. F., Pflüger, V., Duffy, B., Tsror, L., and Manulis, S. 2014. Dickeya solani sp. nov., a pectinolytic plant pathogenic bacterium isolated from potato (Solanum tuberosum). Int. J. Syst. Evol. Microbiol. 64:768-774.

van West, P., and Vleeshouwers, V. G. A. 2004. The Phytophthora infestanspotato interaction. Annu. Plant Rev. 11:219-242.

Weese, T. L., and Bohs, L. 2007. A three-gene phylogeny of the genus Solanum (Solanaceae). Syst. Bot. 32:445-463. 